\title{
THE SURFACE AREA OF CEMENT PASTE AS MEASURED BY NEUTRON SCATTERING - EVIDENCE FOR TWO C-S-H MORPHOLOGIES
}

\author{
Jeffrey J. Thomas* and Hamlin M. Jennings ${ }^{* \dagger}$ \\ Departments of Civil Engineering* and Materials Science and Engineering ${ }^{\dagger}$ \\ Northwestern University, Evanston, IL \\ and \\ Andrew J. Allen \\ Materials Science and Engineering Laboratory \\ National Institute of Standards and Technology, Gaithersburg, MD
}

\begin{abstract}
Small-angle neutron scattering was used to measure the effect of water-to-cement ratio $(\mathrm{w} / \mathrm{c})$ and cement batch variation on the surface area of ordinary Portland cement (OPC) paste after hydration for 28 days at room temperature, and to measure the development of surface area over the first three days of hydration at $30^{\circ} \mathrm{C}$. The 28 day surface area was found to increase with w/c ratio in proportion to the volume of original water-filled space available for reaction product to form. The surface areas of different batches of type I OPC were quite similar, while that of a type II $\mathrm{OPC}$ was some $15 \%$ lower. Early surface area development at $30^{\circ} \mathrm{C}$ followed the heat evolution for the first 24 hours of hydration and then leveled off, suggesting that further heat evolution was associated with reaction product which added little to the surface area. These results support the theory that two different morphologies of the calcium-silicate-hydrate gel reaction product form during cement hydration.
\end{abstract}

\section{Introduction}

Previous small-angle neutron scattering (SANS) measurements of the surface area of cement have resulted in a range of reported values [1-3], depending on extrinsic variables such as the cement composition, age, water-to-cement ratio (w/c), and hydration temperature, and also on some variations in the experimental conditions and data interpretation. This paper reports on the effect of $\mathrm{w} / \mathrm{c}$ on the SANS surface area of ordinary Portland cement (OPC) explicitly, and on the surface area of several different OPC cements produced under identical processing conditions, in order to estimate the amount of variation attributable to compositional differences. An attempt has also been made to clarify some of the assumptions and steps that must be made in calculating surface areas from SANS data. 
One distinct advantage of small-angle scattering techniques is that the surface area can be measured in situ on reacting specimens. This has allowed the early surface area development to be monitored and has resulted in the important discovery [1] that the early surface area develops much more rapidly than is indicated by gas sorption techniques, which are unsuitable for very young specimens. This finding has been confirmed by other techniques, including small-angle X-ray scattering (SAXS) [4], and NMR relaxation [5]. In this study, the surface area was monitored at a higher hydration temperature of $30^{\circ} \mathrm{C}$ for the first time. The surface area of the same OPC cement hydrated with $\mathrm{D}_{2} \mathrm{O}$ was also monitored at $30^{\circ} \mathrm{C}$ in hopes of clarifying the observed dramatic suppression of the reaction kinetics with $\mathrm{D}_{2} \mathrm{O}$ [6]. In both cases the degree of reaction was measured independently by thermal calorimetry, and the comparison of the surface area and the heat evolution is shown to be particularly useful.

\section{Experimental}

Most of the experiments were conducted on OPC specimens that were 28 days old at the time of the SANS measurement. Four different cements, labeled A though D, were used, with compositions as listed in Table I. Cements A, B, and C are type I OPC, and cement D is a type II OPC, designed to have a lower heat of hydration.

To determine the effect of w/c on the SANS surface area, pastes made from cement A were prepared at w/c values ranging from 0.35 to 0.60 . Specimens weighing approximately $250 \mathrm{~g}$ were mixed for 5 minutes by hand and then sealed into plastic cups. Because specimens prepared at w/c greater than about 0.45 tend to bleed, all specimens were then rotated for 48 hours before being stored at room temperature. For cement types B, C, and D, one specimen was made at $\mathrm{w} / \mathrm{c}=0.40$. Two five-year-old OPC specimens that were stored in saturated lime water were also used. These specimens were made with w/c of 0.40 and 0.50 and were also rotated for 48 hours after mixing.

A few days before the SANS experiment, the specimens were unsealed and cut into coupons approximately $0.5 \mathrm{~mm}$ thick using a diamond wafering blade. These coupons were stored under water in small glass vials until just before the experiment, at which time they were transferred to the quartz optical cells used for SANS measurements, along with a few drops of water to maintain saturated conditions.

The real-time hydration experiments were conducted using cement $\mathrm{A}$ and $\mathrm{w} / \mathrm{c}=0.40$. The paste was mixed for 5 minutes and then poured into a quartz optical cell with an internal thickness of $1 \mathrm{~mm}$, which was then sealed. These specimens were immediately placed into the SANS instrument to begin monitoring their early hydration. The specimen holder was maintained at a temperature of $30^{\circ} \mathrm{C}$ throughout the three-day experiment. The heat evolution of cement $\mathrm{A}$ at $\mathrm{w} / \mathrm{c}=0.40$ was measured using thermal calorimetry at $30^{\circ} \mathrm{C}$ for hydration with both $\mathrm{H}_{2} \mathrm{O}$ and $\mathrm{D}_{2} \mathrm{O}$ (See Figure 1). Hydration with $\mathrm{D}_{2} \mathrm{O}$ is significantly slower, and the secondary peak associated with $\mathrm{C}_{3} \mathrm{~A}^{*}$ hydration appears before the $\mathrm{C}_{3} \mathrm{~S}$ hydration peak, as previously noted by King et al. [6].

The SANS measurements were conducted using the NIST/NSF $30 \mathrm{~m}$ SANS instrument at the Center for Neutron Research, National Institute of Standards and Technology, Gaithersburg, MD.

\footnotetext{
* Cement chemistry notation: $\mathrm{C}=\mathrm{CaO}, \mathrm{S}=\mathrm{SiO}_{2}, \mathrm{H}=\mathrm{H}_{2} \mathrm{O}, \mathrm{D}=\mathrm{D}_{2} \mathrm{O}, \mathrm{A}=\mathrm{Al}_{2} \mathrm{O}_{3}$.
} 
TABLE 1

Compositions (Weight \%) of the OPC Cements Used.

\begin{tabular}{|l|c|c|c|c|}
\hline & $\begin{array}{c}\text { Cement A } \\
\text { Type I }\end{array}$ & $\begin{array}{c}\text { Cement B } \\
\text { Type I }\end{array}$ & $\begin{array}{c}\text { Cement C } \\
\text { Type I }\end{array}$ & $\begin{array}{c}\text { Cement D } \\
\text { Type II }\end{array}$ \\
\hline $\mathrm{r}$ & Lafarge $^{1}$ & Ashgrove $^{1}$ & Holnam $^{1}$ & Ashgrove $^{1}$ \\
\hline $\mathrm{SiO}_{2}$ & 18.5 & 21.0 & 20.8 & 22.2 \\
$\mathrm{Al}_{2} \mathrm{O}_{3}$ & 5.3 & 4.1 & 5.3 & 3.2 \\
$\mathrm{Fe}_{2} \mathrm{O}_{3}$ & 2.4 & 3.3 & 2.3 & 4.2 \\
$\mathrm{CaO}$ & 61.3 & 63.5 & 63.5 & 64.5 \\
$\mathrm{MgO}$ & 2.7 & 2.3 & 3.7 & 1.1 \\
$\mathrm{SO}$ & 4.3 & 2.7 & 2.8 & 2.1 \\
$\mathrm{Na}_{2} \mathrm{O}+\mathrm{K}_{2} \mathrm{O}$ & 1.00 & 0.43 & 0.51 & 0.67 \\
\hline $\mathrm{C}_{3} \mathrm{~S}$ & 57.7 & 57 & 54 & 60.0 \\
$\mathrm{C}_{2} \mathrm{~S}$ & 9.6 & 18 & 19 & 18.4 \\
$\mathrm{C}_{3} \mathrm{~A}$ & 10.0 & 6 & 10 & 1.4 \\
$\mathrm{C}_{4} \mathrm{AF}$ & 7 & 10 & 7 & 12.9 \\
\hline
\end{tabular}

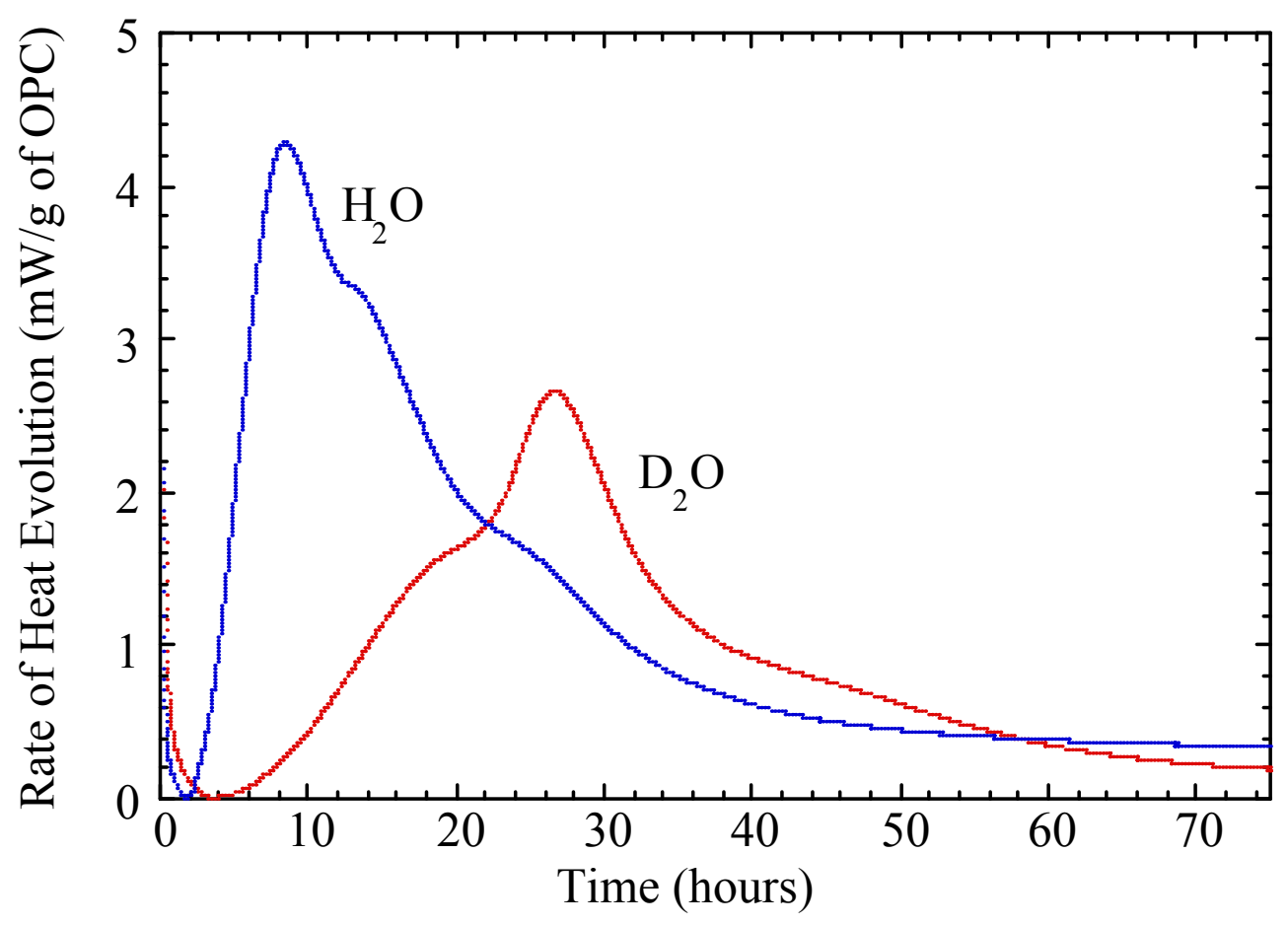

FIG. 1

Rate of heat evolution of cement $\mathrm{A}$ at $30^{\circ} \mathrm{C}$ and w/c $=0.4$, for reaction with $\mathrm{H}_{2} \mathrm{O}$ and $\mathrm{D}_{2} \mathrm{O}$.

${ }^{1}$ Certain commercial materials are identified in order to specify adequately the experimental procedure. Such identification does not imply an endorsement by the National Institute of Standards and Technology, nor does it imply that they are necessarily the best available for the purpose. 


\section{Data Analysis}

The calibrated small angle-scattering intensity, as a function of the scattering angle or associated scattering vector, can be used to determine microstructural properties in hydrating cement such as the gel/pore structure and the total internal surface [1].

To determine the surface area, only the data from the highest scattering angles are used, following the theory developed by Porod [7]. In this regime, the Porod equation holds:

$$
\mathrm{I}=\frac{\mathrm{C}_{\mathrm{P}}}{\mathrm{Q}^{4}}+\mathrm{BGD}
$$

where I is the normalized scattering intensity, Q is the scattering vector $(4 / /) \sin \left({ }_{s} / 2\right),{ }_{s}$ is the angle of scatter, is the neutron wavelength, $C_{P}$ is the Porod constant, and BGD is the background intensity caused by incoherent scattering. When data from the Porod regime is plotted as $\mathrm{IQ}^{4}$ vs. $\mathrm{Q}^{4}$, a linear fit to the data gives the two parameters $\mathrm{C}_{\mathrm{P}}$ and $\mathrm{BGD}$ as the intercept and slope, respectively. $\mathrm{C}_{\mathrm{P}}$ is directly proportional to the surface area:

$$
\mathrm{S}_{\mathrm{V}}=\frac{\mathrm{C}_{\mathrm{P}}}{2 \pi|\Delta \rho|^{2}}
$$

where $S_{V}$ is the surface area per unit specimen volume and $\quad 2$ is the scattering contrast.

The scattering contrast, $|\quad|^{2}$, arises from the difference, , in the intrinsic strength, , of the neutron scattering interaction with the material on each side of a boundary between two phases. In saturated cement pastes the solid/pore surface area is almost entirely within the calcium-silicate-hydrate gel $(\mathrm{C}-\mathrm{S}-\mathrm{H})$, so the appropriate contrast value is that between $\mathrm{C}-\mathrm{S}-\mathrm{H}$ and $\mathrm{H}_{2} \mathrm{O}$. The $\mathrm{C}-\mathrm{S}-\mathrm{H}: \mathrm{H}_{2} \mathrm{O}$ contrast is difficult to calculate because of the variable composition and density of the $\mathrm{C}-\mathrm{S}-\mathrm{H}$ phase. In this work the recently proposed [8] values of $6.7810^{28}$ $\mathrm{m}^{-4}$ for the C-S-H: $\mathrm{H}_{2} \mathrm{O}$ contrast and $1.7510^{28} \mathrm{~m}^{-4}$ for $\mathrm{C}-\mathrm{S}-\mathrm{D}: \mathrm{D}_{2} \mathrm{O}$ were used. These values give surface areas some $20 \%$ higher than those deduced from contrast values commonly used previously [1-3].

Correct determination of the SANS surface area from the raw scattering data depends on three main factors. The data must be corrected for absorption and background scattering, and correctly calibrated against a scattering standard, the correct scattering contrast must be used, and an appropriate range of $Q$ values must be used for calculating the Porod constant. The steps required to normalize the data are discussed elsewhere [1].

Choosing an appropriate range of $\mathrm{Q}$ values to calculate the Porod constant is another important aspect of the surface area calculation. If the lower limit of $\mathrm{Q}$ is too low, the data does not all fall into the Porod regime and the resulting $C_{P}$ and surface area will be too low. While there is no theoretical upper limit on the Porod regime, the rapidly decreasing $\mathrm{Q}^{-4}$ Porod SANS intensity eventually makes it difficult to separate the signal from the background scattering.

Differences in the data calibration of completely independent SANS experiments can result in estimated variations of up to $10 \%$ in the calculated Porod constant, while the various calibration procedures in use at different SANS facilities may lead to variations of up to $20 \%$. One advantage of the experiments discussed here is that, except for the $30^{\circ} \mathrm{C}$ hydration samples, all of the samples were hydrated under the same ambient conditions and all of the data underwent the same calibration procedure. 


\section{Results}

Selection of the correct Porod Q-range

For the SANS instrument configuration and counting times used for these experiments, the upper limit of the reliable data was found to be $\mathrm{Q}=2.0 \mathrm{~nm}^{-1}$. To determine the lower limit of true Porod scattering, several minimum Q values were tested. For each of these Q-ranges, the quality of the linear fit to the $\mathrm{IQ}^{4}$ vs. $\mathrm{Q}^{4}$ plot was determined by calculating the ${ }^{2}$ value. The lower the value of ${ }^{2}$, the better the fit.

Using a minimum Q that is not within the Porod range causes 2 to increase considerably. For the same Q ranges, the background-adjusted intensity, I-BGD, was plotted as a function of Q on a log-log plot, and the slopes of linear fits to these plots were also calculated. From eq. 1 it can be seen that true Porod scattering predicts a slope of -4 . The slopes of the log-log plots, together with the ${ }^{2}$ values and the fitted Porod constants from the Porod plots, are given in Table 2. The best interpretation of these results is that the Porod regime starts at $\mathrm{Q}=1.4 \mathrm{~nm}^{-1}$. All the SANS surface areas reported here were therefore calculated using a Q-range of 1.4 - 2.0 $\mathrm{nm}^{-1}$.

TABLE 2

Porod constant, ${ }^{2}$ value for the $\mathrm{IQ}^{4}$ vs. $\mathrm{Q}^{4}$ linear fit, and slope of the $\log (\mathrm{I}-\mathrm{BGD}) \mathrm{vs} . \log (\mathrm{Q})$ linear fit, for various $Q$ ranges of the data from a 28-d old OPC paste.

\begin{tabular}{|c|c|c|c|}
\hline Q range $\left(\mathrm{nm}^{-1}\right)$ & $\mathrm{C}_{\mathrm{P}}\left(\mathrm{x} 10^{36} \mathrm{~m}^{-5}\right)$ & 2 & slope \\
\hline \hline $1.1-2.0$ & 48.56 & 8.44 & -3.34 \\
$1.2-2.0$ & 57.85 & 5.16 & -3.57 \\
$1.3-2.0$ & 68.95 & 2.45 & -3.82 \\
$1.4-2.0$ & 75.78 & 2.01 & -3.97 \\
$1.5-2.0$ & 78.34 & 2.17 & -4.05 \\
\hline
\end{tabular}

\section{Effect of w/c on surface area}

Table 3 lists the surface areas of the $28 \mathrm{~d}$ old specimens made with different w/c. Column 1 gives the values in the standard SANS units of surface area per unit specimen volume $\left(\mathrm{m}^{2} / \mathrm{cm}^{3}\right)$. The surface area increases monotonically with $\mathrm{w} / \mathrm{c}$, except for the lowest $\mathrm{w} / \mathrm{c}$ of 0.35. Published nitrogen BET results have also indicated an increase in surface area with w/c [9]. BET surface areas are normalized to the mass of the specimen after D-drying, a process which involves equilibrating ground cement paste to a water vapor pressure of $0.5 \mathrm{~m}$ of $\mathrm{Hg}$. To compare the current results to the BET results it is first necessary to convert the SANS values to surface per unit mass of D-dried paste $\left(\mathrm{m}^{2} / \mathrm{g} D D P\right)$. To do this, the density of $28 \mathrm{~d}$ D-dried OPC paste at different w/c was calculated using a model which estimates the volumes of the cement paste phases as a function of clinker composition, w/c, and age [10]. The estimated density of D-dried paste, the SANS surface area per gram of D-dried paste, and the nitrogen BET results of Mikhail and Selim [9] also appear in Table 3. It should be noted that the BET results were for mature OPC specimens (more than 6 months old). The surface area of the lowest w/c specimen did not follow the trend, the reason for this is not known. 


\section{TABLE 3}

Surface areas of cement A at different w/c, all at 28 days, along with the nitrogen BET surface area values of Mikhail and Selim [9]. Statistical standard uncertainties are listed for each surface area value from this study.

\begin{tabular}{|c|c|c|c||c|c|}
\hline $\mathrm{w} / \mathrm{c}$ & $\begin{array}{c}\text { Surface Area } \\
\left(\mathrm{m}^{2} / \mathrm{cm}^{3}\right)\end{array}$ & $\begin{array}{c}\text { Density of } \\
\text { DDP }\left(\mathrm{g} / \mathrm{cm}^{3}\right)\end{array}$ & $\begin{array}{c}\text { Surface Area } \\
\left(\mathrm{m}^{2} / \mathrm{g} \text { DDP }\right)\end{array}$ & w/c & $\begin{array}{c}\text { BET Surface } \\
\text { Area }\left(\mathrm{m}^{2} / \mathrm{g} \text { DDP }\right)\end{array}$ \\
\hline 0.35 & $171.3 \pm 6.3$ & 1.784 & $96.0 \pm 3.5$ & 0.35 & 56.7 \\
0.40 & $162.1 \pm 5.6$ & 1.658 & $97.8 \pm 3.4$ & 0.40 & 79.4 \\
0.45 & $163.2 \pm 5.6$ & 1.549 & $105.4 \pm 3.6$ & 0.50 & 97.3 \\
0.50 & $177.9 \pm 4.8$ & 1.454 & $122.4 \pm 3.3$ & 0.57 & 132.2 \\
0.55 & $181.5 \pm 4.6$ & 1.370 & $132.5 \pm 3.4$ & 0.70 & 139.6 \\
0.60 & $188.9 \pm 5.1$ & 1.296 & $145.8 \pm 3.9$ & & \\
\hline
\end{tabular}

The surface areas of the 5 year old OPC specimens were $162.8 \mathrm{~m}^{2} / \mathrm{cm}^{3}$ for the $0.4 \mathrm{w} / \mathrm{c}$ specimen and $216.4 \mathrm{~m}^{2} / \mathrm{cm}^{3}$ for the $0.5 \mathrm{w} / \mathrm{c}$ specimen. The first value is quite similar to the 28 $\mathrm{d}$ surface areas of the other $0.4 \mathrm{w} / \mathrm{c}$ specimens, while the $0.5 \mathrm{w} / \mathrm{c}$ value is considerably higher than the $28 \mathrm{~d}$ value for the $0.5 \mathrm{w} / \mathrm{c}$ specimen listed in Table 3 . This suggests that at higher w/c the surface area continues to increase past 28 days of hydration.

\section{Effect of cement batch on surface area}

Table 4 lists the surface area values of the $28 \mathrm{~d}$ OPC specimens made from different batches of OPC (see Table 1). These values are relatively constant, with the exception of the type II OPC (cement D) which has a somewhat lower surface area. Type II OPC cements are designed to react more slowly, and this was verified for cement $\mathrm{D}$ with thermal calorimetry. The results shown in Table 4 strongly suggest that any large variations in SANS surface area values for Type I OPC hydrated for $28 \mathrm{~d}$ cannot solely be caused by differences between different OPC batch compositions.

\section{TABLE 4}

Surface areas of the different cements at 28 days and at $\mathrm{w} / \mathrm{c}=0.40$. Statistical standard uncertainties are listed for each surface area value.

\begin{tabular}{|c|c|c|c|}
\hline Cement & $\begin{array}{c}\text { Surface Area } \\
\left(\mathrm{m}^{2} / \mathrm{cm}^{3}\right)\end{array}$ & $\begin{array}{c}\text { Density of } \\
\mathrm{DDP}\left(\mathrm{g} / \mathrm{cm}^{3}\right)\end{array}$ & $\begin{array}{c}\text { Surface Area } \\
\left(\mathrm{m}^{2} / \mathrm{g} \text { DDP }\right)\end{array}$ \\
\hline A (type I) & $162.1 \pm 5.6$ & 1.658 & $97.8 \pm 3.4$ \\
B (type I) & $159.7 \pm 6.1$ & 1.650 & $96.8 \pm 3.7$ \\
C (type I) & $167.9 \pm 5.1$ & 1.653 & $101.6 \pm 3.1$ \\
D (type II) & $137.8 \pm 5.7$ & 1.659 & $83.1 \pm 3.4$ \\
\hline
\end{tabular}




\section{Early surface area development}

Since the surface area and the heat evolution of a cement paste are both primarily due to the reaction of the OPC clinker to form C-S-H gel, the evolution of surface area and the evolution of heat should be related. Figure 2 shows the surface area and the total heat evolved over the first three days of reaction for the $\mathrm{OPC} / \mathrm{H}_{2} \mathrm{O}$ specimen. The surface area development is consistent with the heat evolution for the first 24 hours or so, but then it levels off dramatically while the heat evolution continues to increase. A leveling off of the SANS surface area after an initial period of rapid increase has also been reported in previous work conducted at $20^{\circ} \mathrm{C}$ [1].

Figure 3 shows a similar plot for the $\mathrm{OPC} / \mathrm{D}_{2} \mathrm{O}$ specimen. In this case, the surface area development tracks the heat evolution throughout the 63 hours for which there is surface area data. Because the rate of reaction in $\mathrm{D}_{2} \mathrm{O}$ is approximately three times slower than normal hydration (see Fig. 1), it appears likely that the surface area development has not yet begun to level off. The surface area at a given amount of heat evolution is lower for the $\mathrm{OPC} / \mathrm{D}_{2} \mathrm{O}$ paste, which is consistent with the slower reaction kinetics in the $\mathrm{D}_{2} \mathrm{O}$ system, if it is assumed that some of the activation energies for the hydration reactions are higher than in the $\mathrm{H}_{2} \mathrm{O}$ system.

It should be noted that although plotting the surface area vs. the degree of hydration would be quite useful, the latter is difficult to measure accurately because there are conflicting published values for the $\mathrm{C}_{3} \mathrm{~S} / \mathrm{H}_{2} \mathrm{O}$ heat of hydration, and, more importantly, none at all for $\mathrm{C}_{3} \mathrm{~S} / \mathrm{D}_{2} \mathrm{O}$.

Further experiments involving hydration with $\mathrm{D}_{2} \mathrm{O}$ would be useful.

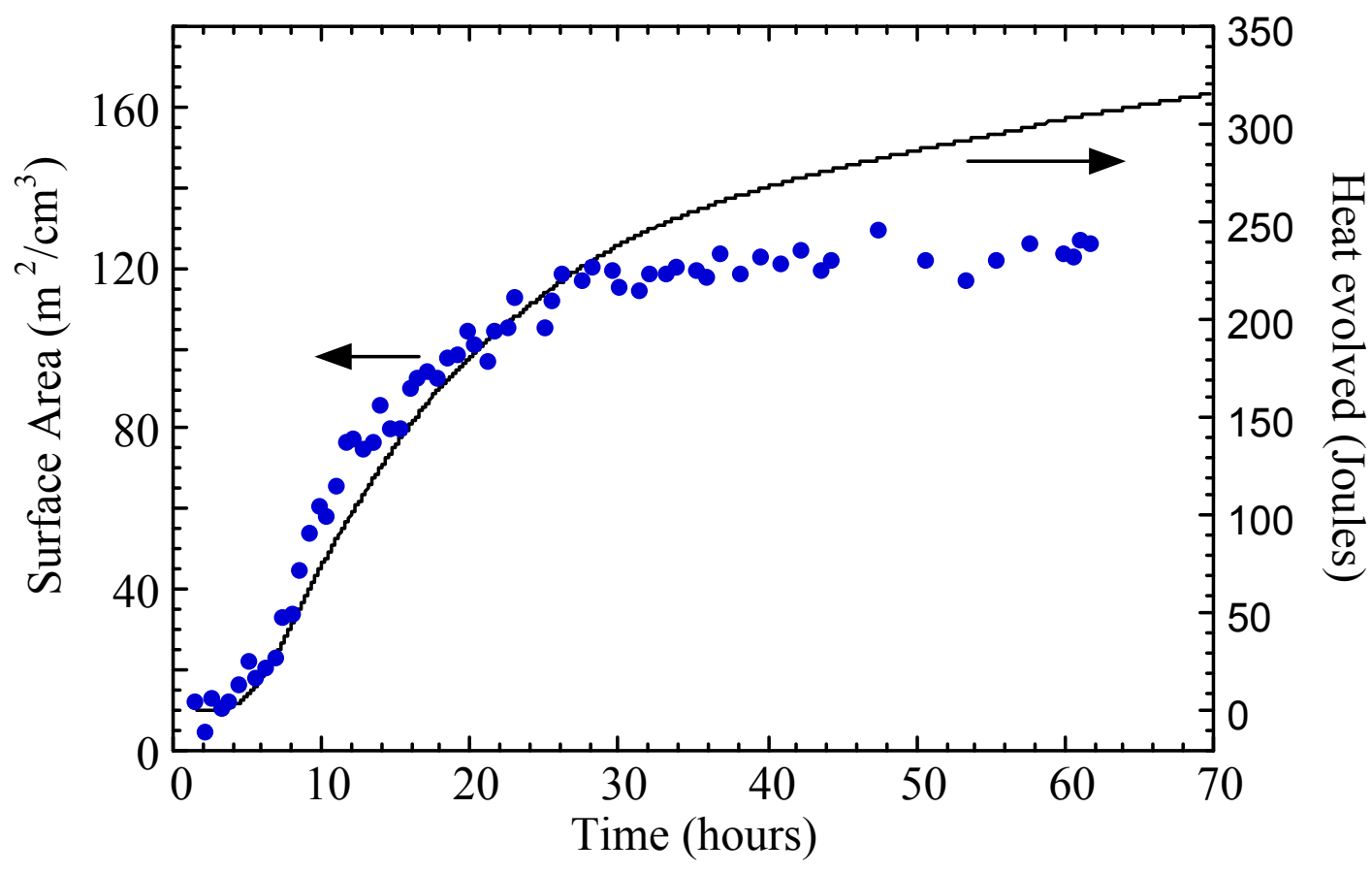

FIG. 2

Surface area (solid circles) and heat evolved (line) for $\mathrm{OPC} / \mathrm{H}_{2} \mathrm{O}$ at $30^{\circ} \mathrm{C}$ and $\mathrm{w} / \mathrm{c}=0.4$. 


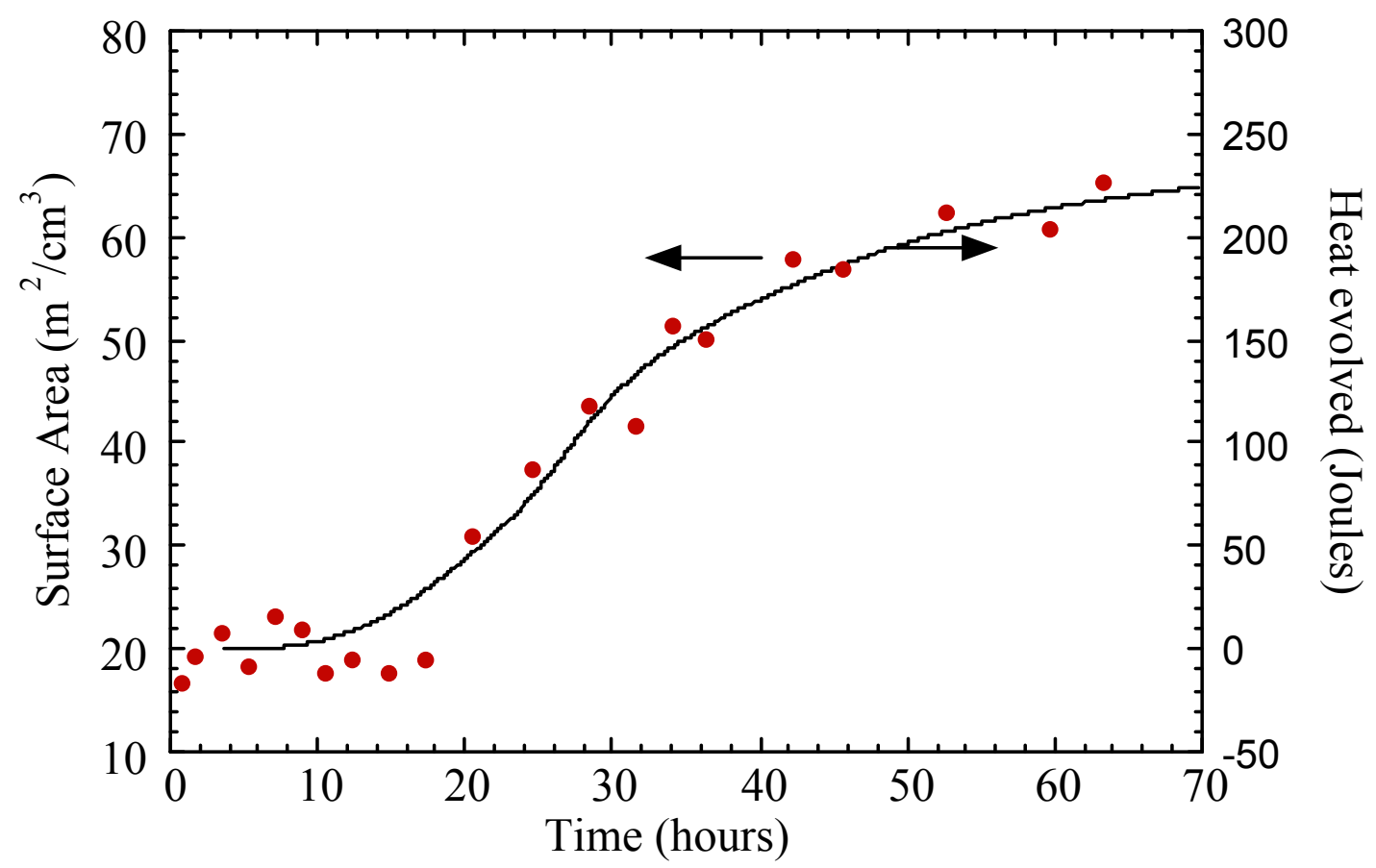

FIG. 3

Surface area (solid circles) and heat evolved (line) for $\mathrm{OPC} / \mathrm{D}_{2} \mathrm{O}$ at $30^{\circ} \mathrm{C}$ and $\mathrm{w} / \mathrm{c}=0.4$.

\section{Discussion}

Because the density of cement paste decreases with increasing w/c, the effect of $w / c$ on the surface area is more dramatic when reported on the basis of dried paste (see Table 3). The variation with w/c is somewhat larger for the BET results of Mikhail and Selim [9] than for SANS, but this may be due to the greater degree of hydration of the BET specimens. Because the degree of hydration of the paste at $28 \mathrm{~d}$ is not strongly affected by w/c, at least for the range of w/c discussed here, these results suggest that the amount of space available for reaction product to form is an important factor in determining the surface area. The volume fraction of water in an as-mixed OPC paste is (ignoring entrapped air):

$$
\frac{\mathrm{w} / \mathrm{c}}{\left(1 / \mathrm{D}_{\mathrm{OPC}}+\mathrm{w} / \mathrm{c}\right)}
$$

where $\mathrm{D}_{\mathrm{OPC}}$ is the density of the OPC clinker, $3.20 \mathrm{~g} / \mathrm{cm}^{3}$. Table 5 lists the initial volume fraction of water for the different $\mathrm{w} / \mathrm{c}$ specimens, calculated using eq. 3 , and the resulting normalized SANS surface area values. The SANS surface area per unit initial pore volume is nearly constant, with the exception of the lowest $\mathrm{w} / \mathrm{c}$ specimen. This indicates that the amount of space available for reaction product is indeed an important factor in determining the 28-day SANS surface area.

Taken together with the evolution of the surface area illustrated in Fig 2, the above observation points to two different morphologies of C-S-H in cement paste: a high surface area form which quickly fills the available pore space during the first few days of hydration, and a low surface area form which predominates at later times. These may well correspond to the so-called "outer-product" and "inner product" types of C-S-H. These results are also in good agreement 
with microscopy studies [e.g. 11] which have identified several different morphologies of C-S$\mathrm{H}$ roughly corresponding to different times in the hydration reaction.

\section{TABLE 5}

Surface area as a function of $\mathrm{w} / \mathrm{c}$, normalized to the amount of initial pore space.

\begin{tabular}{|c|c|c|c|}
\hline w/c & $\begin{array}{c}\text { Surface Area } \\
\left(\mathrm{m}^{2} / \mathrm{cm}^{3}\right)\end{array}$ & $\begin{array}{c}\text { Volume } \\
\text { Fraction } \mathrm{H}_{2} \mathrm{O}\end{array}$ & $\begin{array}{c}\text { Surface Area }\left(\mathrm{m}^{2} \text { per }\right. \\
\left.\mathrm{cm}^{3} \text { of open space }\right)\end{array}$ \\
\hline 0.35 & 171.3 & 0.528 & 324.6 \\
0.40 & 162.1 & 0.561 & 289.0 \\
0.45 & 163.2 & 0.590 & 276.8 \\
0.50 & 177.9 & 0.615 & 289.2 \\
0.55 & 181.5 & 0.637 & 284.7 \\
0.60 & 188.9 & 0.657 & 287.4 \\
\hline
\end{tabular}

It is interesting to note that reported small-angle X-ray scattering (SAXS) results [4] do not show a leveling off of the surface area after a few days, but instead the surface area continues to increase in approximate proportion to the heat evolution until hydration stops. On the other hand, a nuclear-magnetic resonance (NMR) study [5] reported behavior in agreement with the SANS results reported in this work and elsewhere, in that there was little or no increase in surface area between 3 and 28 days. The issue of differences in the measured surface area of cement with different techniques is discussed in detail in a paper currently in preparation [12].

\section{Summary}

The SANS surface area of $28 \mathrm{~d}$ OPC cement paste was found to increase with $\mathrm{w} / \mathrm{c}$ in direct proportion to the volume fraction of water. The surface areas of three different batches of type I OPC prepared the same way were found to be quite consistent, while that of a type II OPC was approximately 15\% lower. Thus, any large variations in SANS surface area values are not likely to be caused solely by compositional differences in the cements used. It should be noted that differences in sample processing, such as the amount of mixing and the conditions under which the specimen is stored, may affect the SANS surface area, and this will be the subject of future work.

The surface area evolution was monitored over the first three days of hydration at $30^{\circ} \mathrm{C}$. The surface area increased rapidly for the first 24 hours, following the heat evolution, and then leveled off. A parallel experiment conducted using $\mathrm{D}_{2} \mathrm{O}$, which slows the reaction by a factor of about three, showed the surface area increasing throughout the experiment, following the heat evolution, and not leveling off within the first three days.

The above results can be interpreted as evidence for two different morphologies of C-S-H: a high-surface area form which rapidly fills the available pore space during the early hydration, and a low surface area form which predominates at later times. 


\section{Acknowledgments}

This work is based upon activities supported by the National Science Foundation under Agreement No. DMR-9423101. Part of this work was supported by the U.S. Department of Energy, Office of Basic Energy Sciences grant number DE-FG02-91ER45460. We wish to acknowledge valuable discussions with R.A. Livingston of the Federal Highway Administration, McLean, VA.

\section{References}

1. A.J. Allen, R.C. Oberthur, D. Pearson, P. Schofield and C.R. Wilding, "Development of the Fine Porosity and Gel Structure of Hydrating Cements," Phil. Mag. B 56, 263 (1987).

2. A.J. Allen, "Time-Resolved Phenomena in Cements, Clays and Porous Rock," J. Appl. Cryst. 24, p. 624 (1991).

3. A.J. Allen, A.H. Baston and C.R. Wilding, "Small-Angle Neutron Scattering Studies of Pore and Gel Structures, Diffusivity, Permeability and Damage Effects," Mat. Res. Soc. Symp. Proc. 137, p. 119 (1989).

4. 4. D.N. Winslow, J.M. Bukowski, and J.F. Young, "The Early Evolution of the Surface of Hydrating Cement," Cem. Con. Res. 24 [6], p. 1025 (1994).

5. W.P. Halperin, J.Y. Jehng, and Y.Q. Song, "Application of Spin-Spin Relaxation to Measurement of Surface Area and Pore Size Distributions in a Hydrating Cement Paste," Magn. Reson. Imaging 12 [2], p. 169 (1994).

6. T.C. King, C.M. Dobson, and S.A. Rodger, "Hydration of Tricalcium Silicate with $\mathrm{D}_{2} \mathrm{O}$," J. Mater. Sci. Lett. 7, p. 861 (1988).

7. G. Porod, "X-Ray Small Angle Scattering of Close Packed Colloidal Systems: I," Kolloid Z. 124 , p. 83 (1951), Part II, ibid, $\underline{125}$, p. 108 (1952).

8. J.J. Thomas, H.M. Jennings, and A.J. Allen, "Determination of the Neutron Scattering Contrast of Hydrated Portland Cement Paste using $\mathrm{H}_{2} \mathrm{O} / \mathrm{D}_{2} \mathrm{O}$ Exchange," Adv. Cem. Bas. Mat. (in press).

9. R.Sh. Mikhail and S.A. Selim, "Adsorption of Organic Vapors in Relation to Pore Structure of Hardened Portland Cement Paste," p. 123 in Symposium of Structure of Portland Cement and Concrete. Highway Research Board Special Report 98 (1966).

10. H.M. Jennings and P.D. Tennis, "Model for the Developing Microstructure in Portland Cement Pastes," J. Am. Ceram. Soc. 77 [12], p. 3161 (1994), and correction in $\underline{78}$ [9], p. 2575 (1995).

11. H.M. Jennings, P.J. Dalgleish, and P.L. Pratt, "Morphological Development of Hydrating Tricalcium Silicate as Examined by Electron Microscopy Techniques," J. Am. Ceram. Soc. $\underline{64}[10]$, p. 567 (1981).

12. 12. J.J. Thomas, H.M. Jennings, and A.J. Allen, "The Surface Area of Hardened Cement Paste as Measured by Various Techniques," Adv. Cem. Bas. Mat. (submitted). 